\title{
Capital Controls and International Trade Finance
}

in a Dual Exchange Rate Regime:... Paul Reding, Jean-Marie Viaene

\section{Weltwirtschaftliches Archiv}

Volume 131 / 1995 / Issue 1 / Article

\section{Nutzungsbedingungen}

DigiZeitschriften e.V. gewährt ein nicht exklusives, nicht übertragbares, persönliches und beschränktes Recht auf Nutzung dieses

Dokuments. Dieses Dokument ist ausschließlich für den persönlichen, nicht kommerziellen Gebrauch bestimmt. Das Copyright bleibt bei den Herausgebern oder sonstigen Rechteinhabern. Als Nutzer sind Sie sind nicht dazu berechtigt, eine Lizenz zu übertragen, zu transferieren oder an Dritte weiter zu geben.

Die Nutzung stellt keine Übertragung des Eigentumsrechts an diesem Dokument dar und gilt vorbehaltlich der folgenden Einschränkungen: Sie müssen auf sämtlichen Kopien dieses Dokuments alle Urheberrechtshinweise und sonstigen Hinweise auf gesetzlichen Schutz beibehalten; und Sie dürfen dieses Dokument nicht in irgend einer Weise abändern, noch dürfen Sie dieses Dokument für öffentliche oder kommerzielle Zwecke vervielfältigen, öffentlich ausstellen, aufführen, vertreiben oder anderweitig nutzen; es sei denn, es liegt Ihnen eine schriftliche Genehmigung von DigiZeitschriften e.V. und vom Herausgeber oder sonstigen Rechteinhaber vor.

Mit dem Gebrauch von DigiZeitschriften e.V. und der Verwendung dieses Dokuments erkennen Sie die Nutzungsbedingungen an.

\section{Terms of use}

DigiZeitschriften e.V. grants the non-exclusive, non-transferable, personal and restricted right of using this document. This document is intended for the personal, non-commercial use. The copyright belongs to the publisher or to other copyright holders. You do not have the right to transfer a licence or to give it to a third party.

Use does not represent a transfer of the copyright of this document, and the following restrictions apply:

You must abide by all notices of copyright or other legal protection for all copies taken from this document; and You may not change this document in any way, nor may you duplicate, exhibit, display, distribute or use this document for public or commercial reasons unless you have the written permission of DigiZeitschriften e.V. and the publisher or other copyright holders.

By using DigiZeitschriften e.V. and this document you agree to the conditions of use.

\section{Kontakt / Contact}

DigiZeitschriften e.V.

Papendiek 14

37073 Goettingen

Email: digizeitschriften@sub.uni-goettingen.de 


\title{
Capital Controls and International Trade Finance in a Dual Exchange Rate Regime: The Belgian Experience Post-Mortem
}

By

\author{
Paul Reding and Jean-Marie Viaene \\ Contents: I. Introduction. - II. The Analytical Framework. - III. Intervention, \\ Capital Controls and Insulation: Comparative Statics. - IV. The Belgian Dual Market \\ as Case Study. - V. Conclusions. - Appendix.
}

\section{Introduction}

$\mathbf{M}$ any countries ${ }^{1}$ have used dual exchange markets to insulate their economies from foreign financial disturbances, while at the same time retaining the benefits of fixed exchange rates for their international trade. Current account transactions are typically routed through an "official market" where the authorities manage the exchange rate through interventions. Capital account transactions are assigned to a "free market" characterized by a pure float.

The literature on dual exchange markets has expanded considerably in recent years. Attention has successively shifted from the insulation properties of the system when the two markets are tightly segmented (see, e.g., Gardner 1985), to the equivalence between dual markets and straightforward controls on capital transactions (see, e.g., Frenkel and Razin 1989) and to the consequences of a dual exchange rate system for fiscal and monetary policy in a two-country model (Guidotti and Végh 1992). Another strand of the literature has

Remark: We benefited from seminar discussions at Erasmus University, K. U. Leuven, Université Laval, U.C. Louvain, Université de Montréal, Innocenzo Gasparini Institute for Economic Research, the Cambridge Summer Meeting of the Econometric Society and University of California, Irvine.

1 France and Italy during brief periods (France: August 1971-March 1974; Italy: January 1973-March 1974). The Belgo-Luxembourg Monetary Union is, to our knowledge, the only country which has operated dual markets on a continuous basis for a period as long as 30 years (from 1955 to 1990). A large number of developing countries have dual or multiple exchange markets. In 1989, the total number of countries reported by the IMF $(1989$, p. 159) as practicing multiple exchange rates was 23 . 
focused on illegal operations between markets, in the sense that current account transactions are diverted to the "free market" in order to cash in on the spread between the two rates (Bhandari and Decaluwe 1987; Gros 1988). Such arbitrage operations obviously weaken the degree of protection offered by the dual markets and reduce its effectiveness.

This paper intends to pursue the analysis of the dual markets' effectiveness in a different direction. Illegal arbitrage between the two markets is not the only factor which undermines the effectiveness of the dual market. Even if the existing administrative separation between markets could be strictly enforced at all times, the authorities might still not reap the expected benefits from dual markets. The reason for this is that changes in payment timing by exporters and importers - i.e. "leads and lags" - are in fact capital movements which, because they are so closely connected to commercial transactions, cannot be assigned to the "free market" and do therefore take place on the official market where they trigger official interventions. Recognizing this threat, authorities often impose specific controls on them. This occurs as well in single exchange regimes (see, e.g., Giovannini 1988, p. 198, for Italy and Claassen and Wyplosz 1982 for France) as in dual markets like Belgium (see, e.g., IMF 1982). Capital controls designed to restrict these types of capital flows typically take the form of contraints on the time period the payments may lead or lag the transaction. Moreover, authorities do also impose controls on the forward operations of exporters and importers. The aim of these controls, which mainly take the form of quantitative restrictions, is to restrict further the arbitrage opportunities between the spot and forward transactions. ${ }^{2}$

\footnotetext{
2 To illustrate, consider the following controls imposed on official market capital flows by the authorities in the Belgo-Luxembourg dual market (Janson 1981). On official spot transactions: (1) control of payment terms by imposing a maximum "lead" (e.g., 3 months) and a maximum "lag" (e.g., 6 months) or even insisting on immediate sale of foreign currency export proceeds; (2) limiting the incentive for residents to accumulate holdings of official foreign currencies by suppressing the interest rate they usually bear and by taxing the capital gain made in case of a parity change; (3) taxing the overdrafts on non-residents' official Belgian franc (BF) deposits with domestic banks. On forward transactions: (1) limitation of forward transactions for exporters and importers to forward cover operations: any profit arising from a forward transaction not connected to a commercial operation is taxed away; (2) imposing zero ceiling on banks' spot position in official foreign currencies. This last measure severely restricts arbitrage between the official spot and forward markets, because it leaves changes in payment terms by exporters and importers as the only arbitrage opportunities. Traders are fined when they do not comply with regulations.
} 
We concentrate our analysis on the official segment of a dual market, postulating complete separation with the free market (except for exogenous illegal transactions between these two markets). Exporters and importers are allowed to change the timing of their payments. To assess how capital controls affect the latter, we model explicitly not only the spot, but also the forward exchange market. To this end, we develop a partial equilibrium model, as standard models of dual exchange markets are not easily extended to risk-averse agents facing an uncertain exchange rate. The same difficulty exists for "collapsing exchange regime models" (e.g., Obstfeld 1988) which could also have been appropriate to analyze speculative behavior resulting from expected parity changes on the official market.

We model exporters and importers as risk-averse, expected utility maximizers who simultaneously decide on the volume of their transactions, the mode of payment and the extent of forward cover. The future official rate is uncertain because interventions do not keep the exchange rate rigidly fixed at its parity and because parity can be changed. Spot market capital controls are modeled as transaction costs, forward controls as quantitative constraints. We are mainly interested in investigating to what extent the exporters' and importers' financial operations in the spot and forward markets undermine, for a given intervention policy, the insulation property of the dual market and in which way capital controls imposed by authorities on spot and forward operations are able to restore it. We show that both types of capital controls increase insulation, as measured by the deviation from uncovered interest parity. This variable combines deviations from covered interest parity with the forward risk premium. Controls on exporters' and importers' spot transactions mainly affect deviations from covered interest parity while quantitative controls of forward operations act through a change in the risk premium.

The paper proceeds as follows. Section II describes the model and examines the properties of its short-run equilibrium. A characterization of its steady state and of its rational expectation solution is relegated to the Appendix. Section III addresses through comparative static analysis the issue of the degree of insulation provided by the dual market, once "lead and lags", uncertainty about the future official exchange rate and capital controls are introduced. Section IV examines the Belgo-Luxembourg dual exchange market as case study. For a period (1975-1985) characterized by numerous exchange crises, we gather empirical evidence on the two variables which determine the degree of insulation: the deviation from covered interest parity and 
the forward risk premium. This allows us to illustrate the behavior of these variables during the episode under review, and to directly test the explanatory power of our theoretical model. Section V concludes the paper.

\section{The Analytical Framework}

\section{Exporters}

Consider a small open economy with the usual types of private agents acting on the official segment of a dual exchange rate system: exporters and importers. The representative domestic exporter (out of $n$ ) takes his production decision for period $t$ knowing that, because of trade credit, net receipts fall due at say, $t+1$. He produces a level of output $X_{t}$ ascribed for exports, subject to a quadratic cost function with domestic input price set equal to one. He faces given foreign currency prices for his output and, troubled by the uncertainty of a nominal exchange rate at the future date, develops a strategy to lessen the riskiness of his position. His domestic currency profit at period $t+1$ reads:

$$
\begin{aligned}
\tilde{\Pi}_{x}=\tilde{w} p^{*} X_{t}+\left(w_{t} r_{t} / i_{t}-\tilde{w}\right) D_{x t}-\left(\tilde{w}-f_{t}\right) H_{x t} \\
\\
-X_{t}^{2} / 2-\beta\left(D_{x t}-\bar{D}_{x}\right)^{2} / 2
\end{aligned}
$$

where " $\sim$ " denotes a random variable; $\tilde{w}$ the domestic price of foreign currency at time $t+1 ; f_{t}$ the one-period forward rate prevailing at time $t$ for delivery at time $t+1 ; p^{*}$ the foreign currency price of exports; $X_{t}$ firm's output and exports; $H_{x t}$ firm's sale of forward foreign currency; $D_{x t}$ the contractual down-payment by foreign customers; $\bar{D}_{x}$ the customary level of receipts paid anticipatedly; $r_{t}-1$, the domestic money rate; $i_{t}-1$ the foreign money rate; and $\beta$ a transaction cost parameter. See the Appendix for a glossary of symbols and variable names. The model involves two periods, the contemporaneous variables are subscripted " $t$ " whereas the one-step-ahead variables have no subscript.

In this capital control environment, the exporter has two possible means of obtaining his payment: first, the exporter can ask his customer to pay at $t$ a down-payment $D_{x t}$ as a result of the contracted deal and second, he can hedge on the forward market for the foreign currency proceeds remaining to be paid at $t+1$.

In the first case, the exporter grants his customer a discount based on the foreign interest rate, $w_{t} D_{x t} / i_{t}$, a proceed which is in turn invested at home to obtain $w_{t} r_{t} D_{x t} / i_{t}$. Advance payments give interest revenues but, whenever $D_{x t}$ departs from the exporter's customary 
prepayments value $\bar{D}_{x}$, the exporter incurs transaction costs (to call on the administrative, financial departments, ...). Monetary authorities closely monitor the deviations $\left(D_{x t}-\bar{D}_{x}\right)$, resort to capital controls to limit their extent and penalize those who do not comply with these regulations. This amounts in our model to an increase in the transaction cost parameter $\beta$, eventually to infinity if enforcement were complete $(0<\beta \leq \infty)$.

In the second case, the merchant can sell the remaining proceeds of foreign currency in the forward market and, in that case, makes a loss if the $t+1$ spot rate exceeds the locked-in forward rate and vice versa.

The exporter is assumed to maximize his expected utility of profits with respect to the choice variables $\left\{X_{t}, D_{x t}, H_{x t}\right\}$ while complying with the capital controls regulation:

$$
\begin{array}{ll}
\text { Maximize } & E U_{x}=\int_{0}^{\infty} U_{x}\left(\Pi_{x}(\tilde{w})\right) h(\tilde{w}) d \tilde{w}, \\
\text { subject to } & H_{x t} \leq p^{*} X_{t}-D_{x t}, \\
& D_{x t} \leq p^{*} X_{t}, \\
\text { and } & D_{x t}, H_{x t} \geq 0,
\end{array}
$$

where $h(\tilde{w})$ is the exporter's subjective probability density function (p.d.f.) of $\tilde{w}$ and $U_{x}($.$) is a strictly concave Von Neumann-Morgen-$ stern utility function.

Constraint (3) stems from capital control measures on the forward market. Only trade-related transactions are authorized and the exporter's forward sales have to be lower than (or equal to) his foreign currency receipts payable at $t+1$. Constraint (4) reflects the fact that the exporter's customer is not a financial intermediary and, therefore, will not engage in a net credit position with respect to the exporter. Lastly, by means of the two nonnegativity restrictions, we introduce the exchange regulation that an exporter may not engage in forward purchases $\left(H_{x t} \geq 0\right)$ and the down-to-earth fact that the customer will not receive a deposit in foreign currency from the exporter $\left(D_{x t} \geq 0\right)$.

As in Newbery and Stiglitz (1981) it is assumed that the first two conditional moments of the subjective p.d.f. exist such that we can write $E(\tilde{w})=\bar{w}$ and $\operatorname{Var}(\tilde{w})=\sigma^{2}$ and approximate $U_{x}($.$) by a second-$ order Taylor expansion at $\tilde{w}^{3}$ Hence, on the basis of the Kuhn-Tucker

\footnotetext{
${ }^{3}$ See also Newbery (1988) who shows that the use of a mean-variance objective function can be justified as a second-order Taylor approximation, with a negligible error, to a more general utility function.
} 
first-order conditions of maximizing (2) we can solve for the decision variables in the case when neither of the constraints (3)-(5) are binding:

$$
\begin{aligned}
& X_{t}=p^{*} f_{t}, \\
& D_{x t}=\bar{D}_{x}-A_{t} / \beta, \\
& H_{x t}=\left(p^{*} X_{t}-D_{x t}\right)-R_{t} / \alpha \sigma^{2},
\end{aligned}
$$

where $\alpha$ is the coefficient of absolute risk aversion, $R_{t}=\left(\bar{w}-f_{t}\right)$ is the forward risk premium, and $A_{t}=\left(f_{t}-r_{t} w_{t} / i_{t}\right)$ is the deviation from covered interest parity. It is clear from (6) $-(8)$ that the exporter simultaneously chooses a production level for export, hedges on the forward market and chooses an optimal down-payment. Equation (6) illustrates the implication of the separation theorem. This property, shown by Ethier (1973), Danthine (1978), Holthausen (1979) and others state that the firm produces a level of exports which depends on the forward rate but is independent of the firm's degree of risk aversion and of the distribution of the exchange rate. The latter are only relevant to the choice of the amount of forward cover, as can be seen from (8). Hence, the production decision is made separately of the down-payment and forward-trading decisions, which are separate activities. Equations (7) and (8) show that the latter are motivated as well by structural as speculative objectives. With an unbiased forward market, i.e. a zero risk premium, $f_{t}=\bar{w}$, the firms will hedge their trade transactions completely and the gains from speculation vanish. This is known as the Full-Hedging theorem (Holthausen 1979; Kawai and Zilcha 1986). With large transaction costs, i.e. $\beta \rightarrow \infty$, or with covered interest parity holding, i.e. $A_{t}=0$, the gains for the firms to deviate from the customary prepayment value disappear.

\section{Importers}

Domestic importers are modeled as trading houses: they buy commodities on the international market at a given product price and retail them locally. At home, we assume that the individual importer $i$ faces the inverted demand curve, $P_{m t}=a_{0}-a_{1} \sum_{i=1}^{m} M_{i t}$, with $M_{i t}$ being the individual import volume and $m$ the number of Cournotcompeting importers on the domestic market. The individual importer's $t+1$ profit takes then the following form, the subscript $i$ being put only when confusion is possible: 


$$
\begin{aligned}
\tilde{\Pi}_{m}= & {\left[a_{0}-a_{1}\left(M_{i t}+\sum_{j \neq i} M_{j t}\right)\right] M_{i t}+\left(\tilde{w}-f_{t}\right) H_{m t} } \\
& -\tilde{w} q^{*} M_{i t}-\left(w_{t} r_{t} / i_{t}-\tilde{w}\right) D_{m t}-\delta\left(D_{m t}-\bar{D}_{m}\right)^{2} / 2,
\end{aligned}
$$

where $q^{*}$ denotes the foreign currency price of imports; $H_{m t}$, the importer's current purchase of forward foreign currency; $D_{m}$, the foreign currency down-payment at period $t ; \bar{D}_{m}$, the customary level of downpayments; and $\delta$ a transaction cost parameter, the other variables having already been defined. Again, the importer has two possible means of executing his payments. First, part of the foreign currency payments due at $t+1$ can be made in advance at the current period $\left(w_{t} D_{m t}\right)$, on which the importer negotiates a discount based on the foreign interest rate $i_{t}$ to compensate him for the amount $r_{t}$ he has to pay on the domestic credit extended to him. Authorities have at times limited this activity by affecting $\delta(0<\delta \leq \infty)$. Second, he can hedge the remainder of his foreign currency bill by purchasing foreign currency to be delivered at $t+1$.

The importer's optimization problem is analogous to the exporter's:

$$
\begin{array}{ll}
\text { Maximize } & E U_{m} \text { with respect to }\left\{M_{i t}, D_{m t}, H_{m t}\right\} \\
\text { subject to } & H_{m t} \leq q^{*} M_{i t}-D_{m t}, \\
& D_{m t} \leq q^{*} M_{i t}, \\
\text { and } & D_{m t}, H_{m t} \geq 0 .
\end{array}
$$

In conformity with foreign exchange prescriptions, the nonnegativity restriction (12) implies that the importer may not sell foreign currency forward $\left(H_{m t} \geq 0\right)$ nor, according to constraint (10), purchase more than the foreign currency payments due at $t+1$. Constraint (11) means that the importer may not anticipate more foreign currency payments than what is due nor, by restriction (12), borrow foreign currency from his supplier. The Kuhn-Tucker first-order conditions of maximization when the constraints (10) to (12) are nonbinding lead to the following solution: ${ }^{4}$

$$
M_{i t}=\left[a_{0}-a_{1} \sum_{i \neq j} M_{j t}-q^{*} f_{t}\right] / 2 a_{1},
$$

\footnotetext{
${ }^{4}$ Importers share with exporters a common attitude towards risk (same utility function). While we can easily allow for diverse precisions and attitudes towards risk, this has no qualitative implications whatsoever except that it would make the exposition less transparent. See Stein (1985) on this.
} 


$$
\begin{aligned}
& D_{m t}=\bar{D}_{m}+A_{t} / \delta, \\
& H_{m t}=\left(q^{*} M_{i t}-D_{m t}\right)+R_{t} / \alpha \sigma^{2},
\end{aligned}
$$

where $A_{t}$ and $R_{t}$ have already been defined. If all $m$ importers are identical $\left(M_{i t}=M_{j t}=M_{t}, \forall i, j\right)$, the symmetric Cournot equilibrium implies (14), (15) and

$$
M_{t}=a_{0}-q^{*} f_{t},
$$

when $a_{1}$ in (13) is set, for simplicity, equal to $1 /(m+1)$. Comparing (6) to (16), one sees that the forward rate affects exports and imports in conformity with the conventional terms of trade analysis.

In the comparison of (8) and (15), recalling that the former represents a forward sale while the latter was defined as a forward purchase, it is worth noting that the speculative parts lead to similar positions, $R_{t} / \alpha \sigma^{2}$, as both traders share the same attitudes towards risk. The hedge parts are different since, while exporters expect to receive foreign currency, importers have to pay in foreign currency. As to downpayments, equations (7) and (14), both optimal levels are guided by their respective target levels but react in opposite way to the market factor $A_{t}{ }^{5}$

\section{Constraints on Spot/Forward Arbitrage}

By substituting (8) in (3), (15) in (10), the constraints brought about by specific controls on the official exchange rate market can be rewritten as follows:

$$
\begin{aligned}
& 0 \leq\left(p^{*} X_{t}-D_{x t}\right)-R_{t} / \alpha \sigma^{2} \leq\left(p^{*} X_{t}-D_{x t}\right), \\
& 0 \leq\left(q^{*} M_{t}-D_{m t}\right)+R_{t} / \alpha \sigma^{2} \leq\left(q^{*} M_{t}-D_{m t}\right) .
\end{aligned}
$$

\footnotetext{
${ }^{5}$ The volumes of exports and imports are priced in foreign currency, invoicing habits playing no role in the model. Assume instead that $j$ and $k$ parameterize the proportion of exports and imports priced in foreign currency, respectively $(0 \leq j, k \leq 1)$. A new solution for the exporter's and importer's behavior is obtained along the line developed so far. First plug (6), (7) and (8) into (2) to obtain the exporter's expected utility of profits and use (14), (15) and (16) to obtain the importer's expected utility of profits. The following partial derivatives are then readily computed: $\partial E U_{x} / \partial j=X_{t}\left(p^{*} f_{t}-p\right) / 2$ and $\partial E U_{m} / \partial k=M_{t}\left(q-q^{*} f_{t}\right) / 2$, where $p$ and $q$ denote the domestic price of exports and imports respectively. If traders set their price at home and abroad such that $p^{*} f_{t}=p$ and $q=q^{*} f_{t}$, then any $j$ and $k$ satisfying $0 \leq j \leq 1$ and $0 \leq k \leq 1$ generates the same expected utility. Hence the choice of the invoice currency is not relevant and, for simplicity, we can select $j=k=1$.
} 
As mentioned already, they confine the exporter and importer to be, respectively, a supplier and demander of forward foreign currency. It is readily seen that at least one of the two upper bounds is always reached depending on the sign of $R_{t}$ and it is impossible for both constraints to be simultaneously binding, except with $R_{t}=0$. Whenever $R_{t}$ is positive, the upper constraint is active for the importer, and the exporter's forward sales are at an interior optimum and vice versa. When exporters anticipate a large future depreciation of the currency relative to the current forward rate $\left(R_{t}>0\right), H_{x t}$ may tend towards zero, the lower bound. However, the latter will never be observed at an equilibrium as the forward rate appreciates in response to the increasing excess demand for the foreign currency, bringing $H_{x t}$ back to an interior optimum while leaving $H_{m t}$ at the upper bound. The same reasoning applies, though in opposite direction, to the importer and the conclusion is similar: the nonnegativity constraints implied by capital controls have no bearing on the problem at hand.

A second layer of constraints, interwoven with the first two, deals with the advance payments. After appropriate substitutions they take the following form:

$$
\begin{aligned}
& 0 \leq \bar{D}_{x}-A_{t} / \beta \leq p^{*} X_{t}, \\
& 0 \leq \bar{D}_{m}+A_{t} / \delta \leq q^{*} M_{t} .
\end{aligned}
$$

Their interpretation is simple: advanced payments cannot be larger than bills and a debtor does not receive payments from the creditor. In substance, they have no legal connotation but reflect common payment practice in trade, their ultimate contribution being the introduction of leads in the model. The upper limit cannot be binding. Why? For example, when $D_{x t}=p^{*} X_{t}$, it follows from the first constraint above that $H_{x t}=0$, i.e. there is no supply of forward foreign currency. Given that agents in the forward market are of two types, either suppliers or demanders, the market is in a state where there are only demanders and, consequently, the equilibrium is degenerate. A similar analysis cannot be applied to the lower bounds, however, because even if $D_{x t}$ and/or $D_{m t}$ were zero, a finite solution for the spot exchange rate $w_{t}$ would still be guaranteed because transactions stem from several other sources, see (17) below. Hence, the possibility of a negative $D_{x t}$ or $D_{m t}$ is not totally ruled out, but the probability of its occurrence is assumed to be very low for sufficiently high levels of $\bar{D}_{x}$ and $\bar{D}_{m}$. All in all, there were originally 81 possible combinations of solutions for the model and we are left now with only three solutions: 
one with constraint (3) binding when $R_{t}<0$, or one with constraint (10) binding when $R_{t}>0$, and one when $R_{t}=0$.

\section{Short-Run Equilibrium}

By aggregating over the respective agents and confronting market demand and supply, we get a market-by-market analysis of the equilibrium condition for the spot and forward currency markets of the official segment of a dual exchange regime. Equilibrium on the spot market is established by the following market-clearing condition:

$$
m D_{m t}+I_{t}=n D_{x t}+S_{t}+u_{t},
$$

or, the demand for the foreign currency must equal its supply. Spot demand consists of $m D_{m t}$, the aggregate down-payment to be paid by importers, and of $I_{t}$, the demand for foreign currency by the central bank for the purpose of interventions. Spot supply consists of $(i)$ the aggregate down-payment received by exporters, $n D_{x t}$, (ii) the spot sale of foreign currency induced by the previous period's speculative decision, $S_{t}$ (see the Appendix for a precise specification) and (iii) a random term representing exogenous illegal transactions, $u_{t}$. Easy substitution of (7) and (14) in (17) leads to the deviations from covered interest parity:

$$
\left(f_{t}-r_{t} w_{t} / i_{t}\right)=\gamma\left[\left(S_{t}+u_{t}-I_{t}\right)+\left(n \bar{D}_{x}-m \bar{D}_{m}\right)\right],
$$

where $\gamma$, defined as $[(m / \delta)+(n / \beta)]^{-1}$, parameterizes the costs of making use of the spot market to shift payments/receipts from period $t+1$ to period $t$ : a higher value for $\gamma$, e.g. due to an increase in $\beta$ and/or $\delta$, means higher costs and a larger deviation from covered interest parity.

The clearing condition for the forward market takes the following form:

$$
m H_{m t}=n H_{x t},
$$

which, making use of (8), (15) and (18), leads to the forward market risk premium:

$$
\left(\bar{w}-f_{t}\right)=\theta\left[\varrho \varepsilon \bar{w}+\varepsilon C+\varepsilon\left(S_{t}+u_{t}-I_{t}\right)\right],
$$

where $\varrho=n p^{* 2}+m q^{* 2}>0, \varepsilon=1 /(1+\theta \varrho)>0$ are constants, and $C=$ $-m a_{0} q^{*}<0$ is the exogenous component of net exports. The parameter $\theta$ is of special interest because it is a short-hand notation for the presence of capital controls on the forward market. In particular, $\theta=\alpha \sigma^{2} /(m+n)$ in absence of capital controls, $\theta=\alpha \sigma^{2} / n$ when importers are constrained $\left(R_{t}>0\right), \theta=\alpha \sigma^{2} / m$ when exporters are con- 
strained $\left(R_{t}<0\right)$. The crucial effect of the legal requirements on the forward market turns out to be the limitation of the number of agents who actively trade in currencies subject to capital controls. The latter increase therefore, as in Giavazzi and Giovannini (1989), "market thinness." This is parameterized by an increase in $\theta$, that in turn increases the risk premium.

To close the model, the official intervention rule by the monetary authorities has to be specified. Under flexible exchange rates, a widely employed rule is the policy that consists in smoothing the deviations from a target exchange rate:

$$
I_{t}=g\left(w^{*}-w_{t}\right)+I_{d t} \quad g \geq 0,
$$

where $w^{*}$ is the parity exchange rate and $I_{d t}$ represents central bank's discretionary demand for foreign currency. The parameter $g$ measures the force of the official intervention policy. In addition, domestic interest rates only change when monetary equilibrium is disturbed by intervention:

$$
r_{t}=r_{t-1}-\omega I_{t} \quad \omega \geq 0,
$$

with $\omega$ taking the value zero if the intervention policy is accompanied by a policy of complete sterilization that leaves the money supply unaffected.

Summing up, under managed floating with (21) as intervention function, the short-term equilibrium consists of the following equations:

$$
\begin{aligned}
& \left(f_{t}-r_{t} w_{t} / i_{t}\right)=\gamma\left[\left(S_{t}+u_{t}-g\left(w^{*}-w_{t}\right)-I_{d t}\right)+\left(n \bar{D}_{x}-m \bar{D}_{m}\right)\right], \\
& \left(\bar{w}-f_{t}\right)=\theta\left[\varrho \varepsilon \bar{w}+\varepsilon C+\varepsilon\left(S_{t}+u_{t}-g\left(w^{*}-w_{t}\right)-I_{d t}\right)\right], \\
& r_{t}=r_{t-1}-\omega g\left(w^{*}-w_{t}\right)-\omega I_{d t},
\end{aligned}
$$

where (21) has been substituted in (18), (20) and (22). This system determines $w_{t}, f_{t}$ and $r_{t}$. The solutions for $w_{t}$ and $f_{t}$ are given by second degree equations because of the exchange rate-domestic interest rate nexus on the LHS of $\left(18^{\prime}\right)$. It is clear by $\left(22^{\prime}\right)$ that the assumption of either no intervention $\left(g=0 ; I_{d t}=0\right)$ or complete sterilization $(\omega=0)$, assumptions predetermining the domestic interest rate, removes the quadratics of the model and provides explicit solutions for $f_{t}, w_{t}$ and $r_{t}{ }^{6}$

${ }^{6}$ Under a strictly fixed exchange rate system (or if an EMS currency has reached one of its extreme bounds), the short-term equilibrium is described by (20), (22) as well as 


\section{Intervention, Capital Controls and Insulation: Comparative Statics}

The model's steady state and the rational expectation solution of the distribution of the exchange rate are presented in the Appendix for the case $\omega=0$. This means that we look for values of $w_{t}, \bar{w}$ and $\sigma^{2}$ which are model-generated and correspond to a rational expectation equilibrium. It is easily apparent from (A.1) that if the two sources of randomness $\left(\tilde{u}, \tilde{I}_{d}\right)$ are normally distributed, so is $\tilde{w}$. If this is the case, this solution validates our assumption that traders have a subjective distribution of $\tilde{w}$ which can be characterized by the first two moments.

This being established, we concentrate on the short-run properties of the model, i.e., considering $\bar{w}$ and $\sigma^{2}$ as given. As under managed float it is not possible to compute the reduced form because of nonlinearities in $w_{t}$ and $r_{t}$, the comparative static analysis for $f_{t}, w_{t}$ and $r_{t}$ is performed by differentiating the system. These variables are in turn used to construct the composite variables $A_{t}, R_{t}$ and $\left(A_{t}+R_{t}\right)$, the last variable being the deviation from uncovered interest parity (DUIP).

Table 1 summarizes the comparative static effects of increases in the instruments of the central bank: the intensity of official interventions, denoted by $g$; a discretionary demand for foreign currency, denoted by $I_{d}$; the intensity of the capital controls on the spot market, described by parameter $\gamma$, and on the forward market, described by parameter $\theta$. The purpose of our analysis is to find in which way changes in central bank's actions affect the six variables of interest. ${ }^{7}$ The degree of insulation provided by the dual market cum capital controls can be assessed by looking at the individual behavior of the exchange and interest rates. A more complete and synthetic picture is obtained, however, by looking at DUIP. Indeed, for a given $\bar{w}$ and

(18) solved for $I_{t}$. Intervention is, in this context, compulsory and given by an amount that clears the spot market, i.e., (18) inverted. The solution for the three endogenous variables $I_{t}, f_{t}$ and $r_{t}$ is then also explicit and unique.

7 Also important is to know how these policy measures affect the welfare of the traders on the market. To that end, find the income transfer for exporters and for importers, $Y_{x}$ and $Y_{m}$ respectively, that is the amounts agents are willing to pay or expect to receive for the policy action. They are implicitly defined from the merchants' expected utility expressions: insert (6) to (8) and (14) to (16) in the respective utility formulae twice, one with and one without policy action and take their difference. Central bank's policy actions then lead to a welfare improvement for the merchants if $m Y_{m}+n Y_{x}>0$. A sufficient condition for this is $\left[\eta_{x}-(3 m-1) /(m+1)\right] d f>0$ where $\eta_{x}$ is the export supply price elasticity. For actions implying $d f>0$ (depreciation) global welfare is improved if $\eta_{x}>(3 m-1) /(m+1)$ and vice versa: home exports are then subsidized and imports taxed. If $m=1$ we get the monopoly condition, $\eta_{x}>1$. For $m=\infty$ the competitive condition is $\eta_{x}>3$. 
Table 1 - Central Bank's Policy Instruments ${ }^{\text {a }}$

\begin{tabular}{|l|cccccc|}
\hline & $f_{t}$ & $w_{t}$ & $r_{t}$ & $A_{t}$ & $R_{t}$ & $\left(A_{t}+R_{t}\right)$ \\
\hline$g$ & $s\left(w^{*}-w_{t}\right)$ & $s\left(w^{*}-w_{t}\right)$ & $-s\left(w^{*}-w_{t}\right)$ & $-s\left(w^{*}-w_{t}\right)$ & $-s\left(w^{*}-w_{t}\right)$ & $-s\left(w^{*}-w_{t}\right)$ \\
$I_{d}$ & + & + & - & - & - & - \\
$\gamma$ & $s\left(A_{t}\right)$ & $-s\left(A_{t}\right)$ & $-s\left(A_{t}\right)$ & $s\left(A_{t}\right)$ & $-s\left(A_{t}\right)$ & $s\left(A_{t}\right)$ \\
$\theta$ & $-s\left(R_{t}\right)$ & $-s\left(R_{t}\right)$ & $-s\left(R_{t}\right)$ & $-s\left(R_{t}\right)$ & $s\left(R_{t}\right)$ & $s\left(R_{t}\right)$ \\
a $^{\prime} s()=$. sign corresponds to the sign of argument. & & \\
\hline
\end{tabular}

foreign interest rate, the lower the domestic interest rate and/or the exchange rate is, the better the insulation is and the larger $\left(A_{t}+R_{t}\right)$ is. DUIP therefore adequately measures changes in the degree of insulation. ${ }^{8}$ The focus of our exposé is on changes in $\gamma$ and $\theta$, the other instruments being analyzed by analogy.

An increase in the intensity of capital controls on the spot market (stricter regulations bearing on payment patterns) is represented by an increase in the parameter $\gamma$. It appears that the effects of an increase of $\gamma$ depend on the initial value of $A_{t}$ : an increase in $\gamma$ increases the absolute value of $A_{t}$ with $A_{t} \rightarrow 0$ when $\gamma \rightarrow 0$. Assume a positive $A_{t}$. This increase in $\gamma$ then induces an increase in $D_{x t}$ and a decrease in $D_{m t}$ : each agent tries to respect more closely the customary prepayment terms $\bar{D}_{x}$ and $\bar{D}_{m}$. An excess supply of foreign currency is observed on the spot market, prompting a decrease in $w_{t}$, purchases of foreign currency by authorities and a decrease in domestic interest rates. This amounts to an overall increase in $A_{t}$. The increase in $D_{x t}$ and decrease in $D_{m t}$ imply an excess demand for forward currency which calls for an increase in the forward rate $f_{t}$. The risk premium $R_{t}$ declines, but the decline is not sufficiently large enough to offset completely the increase in $A_{t}$, so that the DUIP also increases. Hence, stricter regulations concerning payments on the official spot market unambiguously increase the degree of insulation of the domestic economy.

The imposition of constraints on exporters' and importers' forward operations can be modelled as an increase in the parameter $\theta$. When $R_{t}>0$, an increase in $\theta$ reflects the curtailment of the importers'

\footnotetext{
${ }^{8}$ Changes in deviations from covered interest parity seem therefore to signal correctly the direction of changes in the economy's degree of protection only when capital control measures are designed to mainly affect spot operations (as is, in this model, the case for $\gamma$ but not for $\theta$ ). When, however, capital controls are directed towards forward operations, deviations from covered interest parity may be a misleading indicator of the degree of insulation.
} 
forward operations: importers are obliged to restrict their purchase of forward currency to their import payments. When $R_{t}<0$, the increase in $\theta$ reflects the constraints on the exporters' forward transactions. Starting from an initial $R_{t}>0$, an increase in $\theta$ acts as a forward market intervention: the demand for currency is reduced, which drives down the forward rate. The resulting decrease in $A_{t}$ induces arbitrage operations between spot and forward markets: $D_{m t}$ decreases and $D_{x t}$ increases, net receipts are shifted from period $t+1$ to period $t$. This acts as a support for the spot exchange rate: $w_{t}$ decreases, as do intervention sales of foreign currency and, therefore, the domestic interest rate. Although $A_{t}$ decreases, DUIP increases as the increase in the forward risk premium outperforms the decrease in $A_{t}$.

Hitherto, in our discussion of the official market of the dual exchange system only policy changes emanating from the central bank have been considered. But how well does the dual market insulate the domestic economy from shocks emanating from the rest of the world? Table 2 outlines the effects of three such shocks: (i) speculative attacks in the form of an anticipated change in the future official exchange rate, (ii) a foreign interest rate shock $(i-1)$ and (iii) a positive shock to the current account $(C)$. Only a change in $\bar{w}$ is considered extensively, a change in $C$ and $(i-1)$ involving a reasoning known by now.

An increase in $\bar{w}$ induces an excess demand for forward currency for the purpose of speculation; $f_{t}$ increases, but proportionally less than $\bar{w}$. Analytically, this is so because $\theta \varrho \varepsilon \bar{w}$ in (20) is positive and, at impact, creates a positive risk premium. This wedge vanishes, however, when risk neutrality is assumed across the board, i.e., when $\theta=0$. Intuitively, an increase in $f_{t}$, which would have been proportional to the increase in $\bar{w}$, would have left an excess supply of forward currency. Why? There are two reasons. First, with a higher forward rate ex-

Table 2 - Insulation Properties of a Dual Market

\begin{tabular}{|l|cccccc|}
\hline & $f_{t}$ & $w_{t}$ & $r_{t}$ & $A_{t}$ & $R_{t}$ & $\left(A_{t}+R_{t}\right)$ \\
\hline $\bar{w}$ & + & + & + & + & + & + \\
$g^{\mathrm{a}}$ & - & - & + & + & + & + \\
$\gamma^{\mathrm{a}}$ & + & - & - & + & - & + \\
$\theta^{\mathrm{a}}$ & - & - & - & - & + & + \\
$i-1$ & - & + & + & + & + & + \\
$C$ & - & - & - & - & + & + \\
a Second partial derivative of variable in column with respect to $\bar{w}$ and parameter \\
in line.
\end{tabular}


porters increase their exports and their forward sales. Second, given the increase in $f_{t}$, a positive $A_{t}$ appears (or increases) leading exporters to reduce the part of total receipts payable today and to increase thereby their forward sales. By analogy, the opposite reasoning holds for importers who wish on balance to reduce their forward purchases. The risk premium $R_{t}$ has therefore to increase, which stimulates agents to speculate, i.e., exporters (importers) to sell (buy) less (more) forward currency. The spot rate $w_{t}$ increases as a resultant of the excess demand for spot currency, the domestic interest rate increases by the intervention rule, $A_{t}$ and $\left(A_{t}+R_{t}\right)$ increase as a whole.

So far, the above reasoning corroborates the known result that, with imperfectly mobile capital flows ( $\gamma$ strictly positive), the domestic exchange and interest rates are partly shielded from speculative disturbances. The novelty of our approach is, however, to show how the response of each endogenous variable to a change in $\bar{w}$ is shaped by the magnitude of the key parameters of the model. ${ }^{9}$ It is shown in rows 3 and 4 of Table 2 that both types of capital controls $(\gamma, \theta)$ diminish the increase in $w_{t}$ and $r_{t}$, brought about by the anticipated increase in $\bar{w}$ and thereby reinforce DUIP. The same results are obtained with more active interventions $(g)$, although in this case the increase in the domestic interest rate is magnified.

\section{The Belgian Dual Market as Case Study}

We try hereafter to assess the model's empirical relevance by focusing on the extent of insulation which the Belgian economy has enjoyed thanks to the presence of a dual market and to the various capital controls the authorities have imposed on "official market" capital flows. The $1975-85$ period is in this respect particularly appropriate. Authorities faced during this period repeated exchange crises due to the sizeable overvaluation of the Belgian franc (BF) and to the difficulty to reestablish the credibility of the exchange rate parity after the 1982 devaluation. ${ }^{10}$ During these speculative episodes, the pressures

\footnotetext{
9 This is done by taking the second partial derivative of the variables of interest with respect to $\bar{w}$ and $\gamma, \theta$ or $g$.

10 We stop at 1985 with our sample period because the authorities' macroeconomic policy had by this time reestablished the exchange target's credibility. Moreover, agents and authorities started to anticipate, after 1985, the abolition of the dual market in the wake of the upcoming European capital market integration. It is therefore questionable whether the dual market had in these circumstances still a normal functioning.
} 
on the official exchange market were, to a large extent, the consequence of "official" capital outflows engineered by exporters and importers. Authorities severely limited the extent of these outflows by imposing controls on traders' spot and forward transactions. See the Appendix for the sources of our data.

\section{A Measure of the Expected Level and} Conditional Variance of the Future Exchange Rate

To investigate the behavior of $R_{t}$ and DUIP ( $A_{t}$ being directly observable), it is necessary to develop a measure for the unobservables, $\bar{w}$ and $\sigma^{2}$. Given that BF is an EMS currency, we start by assuming that agents consider two possible regimes for next period's exchange rate: regime 0 , with parity fixed at its present level $w_{0}^{*}$; regime 1 with a new parity $w_{1}^{*}$.

In regime 0 , agents determine $\bar{w}$ according to a target zone model. In such a model, the exchange rate exhibits strong mean reversion because of the presence of upper and lower limits to its fluctuations. The expected depreciation of the exchange rate is therefore negatively linked in a nonlinear way to the exchange rate's position in the band. We use the specification developed by Rose and Svensson (1991) in which the change in the (log of the) exchange rate is regressed on the current deviation of the exchange rate from parity (both in logs) as well as on the square and the cube of this deviation. This specification is estimated each month on end of month data for the official Belgian franc/Deutsche mark (BF/DM) rate. Months during which a parity change occurred have been excluded. The estimation method involves rolling regressions on the last 24 months. The estimated specification is then used to forecast the first and second moments of next period's distribution of the level of the exchange rate: $E_{t}\left(w_{t+1} \mid w^{*}=w_{0}\right)$ is directly derived from the regression's one-period-ahead forecast; the conditional variance is derived from the sample period residuals (after appropriate conversion of the exchange rate from logs into levels).

In regime 1, we assume that agents expect the future spot rate to coincide with the new parity: $E_{t}\left(w_{t+1} \mid w^{*}=w_{1}^{*}\right)=w_{1}^{*}$. The conditional variance of $\tilde{w}$ in this regime is assumed to be identical to that in regime $0: \sigma_{1, t}^{2}=\sigma_{0, t}^{2}$.

Denoting by 'prob, the probability, assessed in $t$, that regime 1 will be observed in period $t+1$, we may now define $\bar{w}_{t}$ as the conditional expectation of the future exchange rate when both regimes are possible: 


$$
\begin{aligned}
\bar{w}_{t}= & E_{t}\left(w_{t+1}\right)=\operatorname{prob}_{t} E_{t}\left(w_{t+1} \mid w^{*}=w_{1}^{*}\right) \\
& +\left(1-\operatorname{prob}_{t}\right) E_{t}\left(w_{t+1} \mid w^{*}=w_{0}^{*}\right) .
\end{aligned}
$$

Similarly, it can be easily shown that the conditional variance of the distribution of the exchange rate across the two possible regimes is, under the hypothesis that $\sigma_{1, t}^{2}=\sigma_{0, t}^{2}$, given by:

$$
\begin{aligned}
\sigma_{t}^{2}= & \sigma_{0, t}^{2}+\left[E_{t}\left(w_{t+1} \mid w^{*}=w_{1}^{*}\right)-E_{t}\left(w_{t+1} \mid w^{*}=w_{0}^{*}\right)\right]^{2} \\
& \operatorname{prob}_{t}\left(1-\text { prob }_{t}\right) .
\end{aligned}
$$

To give empirical content to (23) and (24), it is necessary to develop a measure for the probability of a parity change $\left(\right.$ prob $\left._{t}\right)$ and for the expected new parity $\left(w_{1}^{*}\right)$.

The probability of a regime change is constructed under the following hypothesis of expectation formation: ${ }^{11}$ agents observe at each moment the deviation between the spot rate and the upper (lower) margin rate. At the latter rate, authorities' interventions become infinitely elastic with respect to the exchange rate. It seems reasonable to postulate that, during a given period, the more frequently the spot rate hits or comes close to the upper (lower) margin rate, the higher will be agents' subjective probability of an imminent change in parity. On this basis the probability, assessed at the end of month $t$, that the parity will have changed by the end of month $t+1$ (prob) is defined in the following manner for the case when the anticipated parity change is a devaluation:

$$
\operatorname{prob}_{t}=\frac{1}{3 N_{t}}\left(N_{1 t}+N_{2 t}+N_{3 t}\right)
$$

$N_{i t}$ being the number of days in month $t$ during which the spot rate has been above the (month $t$ ) parity rate $w^{*}$ by at least $x_{i}$ percent. Given that the maximum deviation from parity is 2.25 percent, in accordance with EMS rules, we choose $x_{1}=1.875, x_{2}=2.000$ and $x_{3}=2.125 . N_{t}$ is the total number of business days in month $t$. Note that, because exchange rates are observed at the end of the month, prob $_{t}$ was set equal to 0 for the months during which parity changes occurred.

\footnotetext{
${ }^{11}$ It departs from the "collapsing exchange regime" literature in that it does not directly connect the probability of devaluation to the level of international reserves. It seems however quite clear that the level of reserves did not play a critical role in agents' expectation formation, as the Belgian central bank and the government still had ample opportunities to borrow reserves.
} 
The expected future parity in case of a change in regime, $w_{1}^{*}$, is equal to the spot exchange rate which would reestablish the equilibrium real exchange rate with respect to the Deutsche mark. The relevant real exchange rate is based on wage costs in manufacturing industries. The reference situation reflecting the equilibrium is the $1970-73$ period. The equilibrium spot exchange rate $w_{1 t}^{*}$ is therefore given by:

$$
w_{1 t}^{*}=\frac{L C B_{t}}{L C D_{t}} \cdot w_{(70-73)}^{*},
$$

where $L C B_{t}$ and $L C D_{t}$ are indexes (base 70-73) of labor costs in Belgian and German manufacturing industries, respectively, and $w_{(70-73)}^{*}$ is the $1970-73$ average $\mathrm{BF} / \mathrm{DM}$ parity rate.

\section{Deviations from Uncovered Interest Parity}

DUIP combines $A_{t}$ and $R_{t}$. Figure 1 displays $A_{t}$ in panel (a) as well as the constructed series on $R_{t}$ in panel (b) and DUIP in panel (c), all defined in annualized percentages. Data refer to one-month interest $\mathrm{BF}$ and $\mathrm{DM}$ interbank rates and to $\mathrm{BF} / \mathrm{DM}$ spot and forward rates, measured at the end of month. Dates of EMS realignments concerning the BF/DM rate are indicated by vertical lines in Figure 1.

The deviations from interest parity exhibited in panel (a) are defined as the annualized difference between the domestic interest parity levels, i.e., as excess returns. $A_{t}$ appears at times very sizeable (up to 15 percent) although on average very small, 0.5 percent. This already suggests, as more explicitly argumented below, that deviations occur during specific speculative episodes when capital controls effectively constrain the exporters' and importers' behavior. A comparison of panels (a) and (c) clearly shows that $A_{t}$ is dwarfted by the forward risk premium. Although $A_{t}$ and DUIP are strongly correlated (the sample correlation coefficient is 0.55 ), $A_{t}$ never exceeds 15 percent, when, at the same time DUIP comes close to 200 percent (annualized monthly rate).

A comparison of panels (b) and (c) indeed shows that the forward risk premium is usually fairly small, but rises to its extreme values when agents anticipate an imminent devaluation. The size of the extreme values of the risk premium appears nevertheless very large when compared to estimates of risk premia reported elsewhere. Analyzing survey data for floating currencies, Froot and Frankel (1989) report one-month risk premia of maximum 20 percent p.a. Svensson (1990) 
Figure 1 - Deviations from Covered and Uncovered Interest Parity and Forward Risk Premium (Annualized percentage)
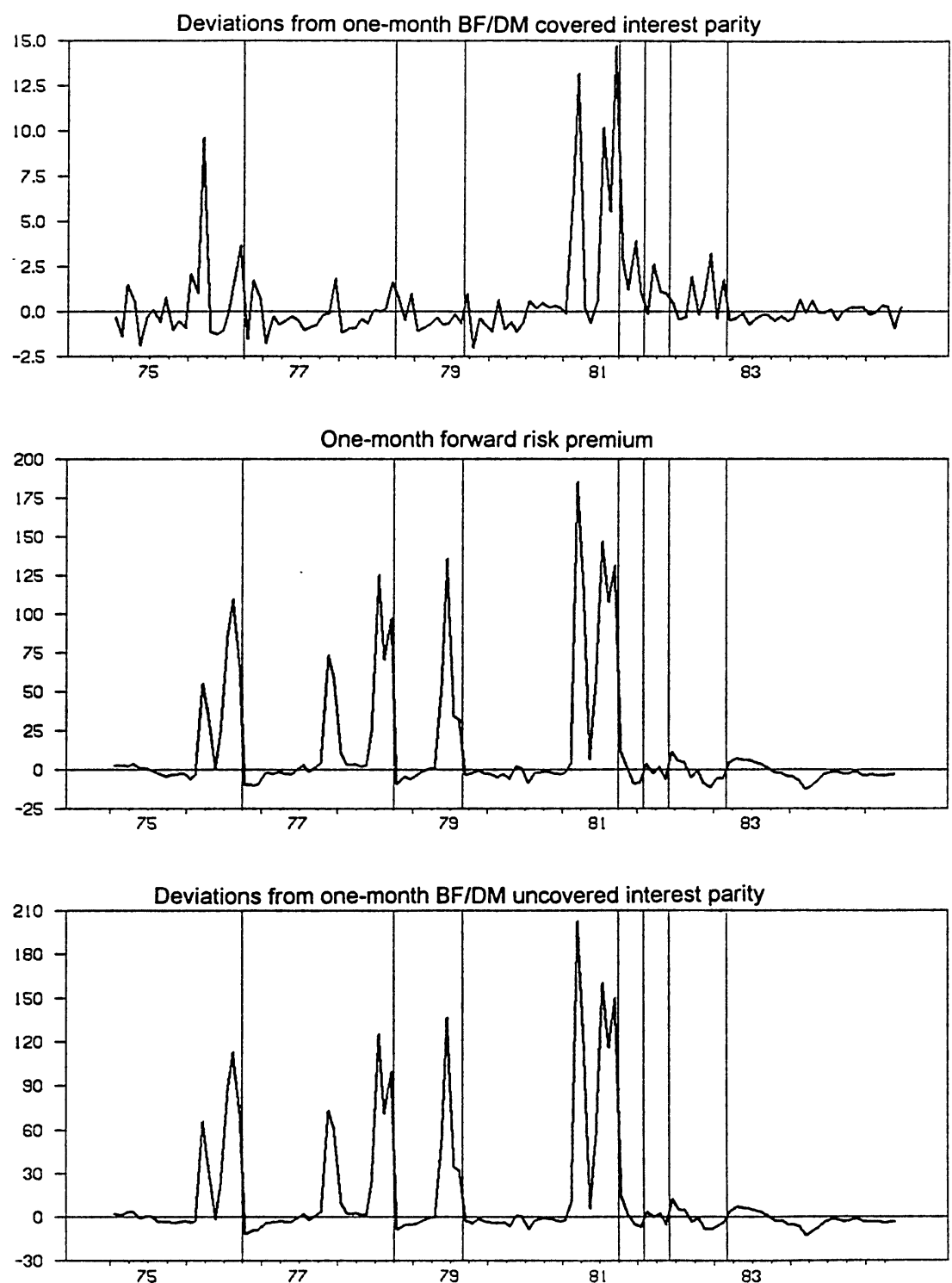
notes that in a target zone, risk premia arising from expected changes in parity may become important but remain nevertheless small relative to the expected rate of parity change. In our case, the risk premia come close to the magnitude of expected changes in the exchange rate, once both are expressed in percent p.a. Therefore, under the hypothesis that the approximation of $\bar{w}$ is reasonable, ${ }^{12}$ these abnormally large risk premia may well be the direct consequence of capital controls imposed by authorities on the forward market. As discussed previously, these kinds of capital controls decrease the number of "speculators" in the market and therefore increase the absolute value of risk premia. This reinforces the increase in the risk premium which an anticipated depreciation of the spot rate would, independently of any capital control measure, bring about. If this interpretation is correct, agents' risk aversion combined with authorities' capital controls on the forward market have indeed very much contributed to the shielding of the spot rate and the domestic interest rate.

\section{Estimates for $A_{t}$ and $R_{t}$}

We conclude our empirical investigation by briefly considering estimates of the reduced forms for $A_{t}$ and $R_{t}$. As indicated in Table 3 , both variables are regressed on the exogenous variables as they can be derived from the short-run equilibrium version of the model presented in Section II: the future expected rate $E_{t}\left(w_{t+1}\right)$ (scaled by $w^{*}$, the parity exchange rate), the foreign interest rate $\left(i_{t}-1\right), C_{t}$ and $I_{d t}$. See Tables 1 and 2 for the theoretical sign of each variable. The current account, defined on a transactions basis, is introduced to capture the exogenous supply of forward currency on the official market, $C_{t}$ in (20). ${ }^{13}$ Discretionary interventions $I_{d t}$ are defined as interventions which are not explained by the reaction function which links interventions to deviations of the exchange rate from its target rate. Our empirical interven-

\footnotetext{
12 To gain some preliminary comparative evidence on the quality of our measure of $\bar{w}$, we performed some of the tests developed by Frankel and Froot (1986) for their survey data on exchange rate expectations and obtained results similar to theirs. In particular, expected depreciation is strongly correlated with the risk premium. Systematic forecasting errors are also present. This points, in our case, where forecasting the future rate involves assessing the probability of a regime change, to a typical peso problem (see Krasker 1980).

${ }_{13}$ Variable $C_{t}$ in (20) stands for that part of the current account which is not sensitive to changes in the exchange rate between $t$ and $t+1$. Given the one-month horizon in our data, we approximate this by the current accounts transactions observed in period $t$.
} 
Table 3 - Deviation from Covered Interest Parity and Forward Risk Premium

\begin{tabular}{|l|cc|cc|}
\hline \multirow{2}{*}{$i=1,2$} & \multicolumn{2}{|c|}{ Equation I } & \multicolumn{2}{c|}{ Equation II } \\
\cline { 2 - 5 } & Parameter & $t$-statistic & Parameter & $t$-statistic \\
\hline$\alpha_{i}$ & -2.14 & 5.02 & 10.89 & 1.63 \\
$\beta_{i}$ & 44.35 & 6.67 & $1,032.48$ & 31.59 \\
$\xi_{i}$ & 0.069 & 2.75 & 0.371 & 1.43 \\
$\vartheta_{i}$ & 0.352 & 4.85 & -3.73 & 2.74 \\
$\eta_{i}$ & -0.046 & 4.50 & -0.040 & 0.87 \\
$\lambda_{i}$ & -0.891 & 1.62 & 0.061 & 2.82 \\
$\varrho$ & - & - & 0.810 & 9.36 \\
$\mathrm{R}^{2}$ & 0.54 & & 0.96 & \\
$\mathrm{DW}$ & 1.58 & & 2.31 & \\
\end{tabular}

Note: FIML estimation; monthly data 1975:1-1985:5; symbols for variables in the Appendix; $V_{t}$ is the stochastic term of equation II; see (24) and (25) for the construction of $\sigma_{t}^{2}$ and $I_{d t}$. The equations I and II are:

$\left(f_{t} \frac{i_{t}}{w_{t}}-r_{t}\right) 1,200=\alpha_{1}+\beta_{1}\left(\frac{E_{t}\left(w_{t+1}\right)}{w_{t}^{*}}-1\right)+\xi_{1} C_{t}+\vartheta_{1}\left(i_{t}-1\right)+\eta_{1} I_{d t}+\lambda_{1} \sigma_{t}^{2}$

$\left(\frac{E_{t}\left(w_{t+1}\right)}{f_{t}}-1\right) 1,200=\alpha_{2}+\left[\sigma_{t}^{2}\right]^{\lambda_{2}}\left\{\beta_{2}\left[\frac{E_{t}\left(w_{t+1}\right)}{w_{t}^{*}}-1\right]+\xi_{2} C_{t}+\vartheta_{2}\left(i_{t}-1\right)+\eta_{2} I_{d t}\right\}$ $+\varrho V_{t-1}$.

tion function captures the essence of (21) but takes account, through a logistic specification, of the nonlinearities involved by the 2.25 percent target zone for the BF/DM exchange rate. A "leaning against the wind" term is also added.

Discretionary interventions are thus computed as the residuals of the following intervention function ( $t$-stat. in parentheses):

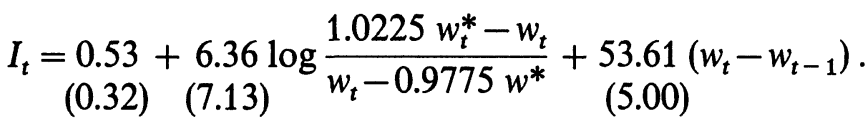

$$
\begin{aligned}
& \mathrm{R}^{2}=0.40 \quad \mathrm{D}-\mathrm{W}=1.68
\end{aligned}
$$

Table 3 reports the results of simultaneous FIML estimation of the equations for $A_{t}$ and $R_{t}$. The latter equation has a nonlinear specification, as the conditional variance of the exchange rate $\sigma_{t}^{2}$ necessarily affects the risk premium in a multiplicative way, see (20). The FIML technique also allows the taking into account of cross-correlations between the stochastic terms of both equations as well as of first-order 
autocorrelation in the risk premium equation. With the exception of the current account variable in the covered interest parity equation and the foreign interest rate in the risk premium equation, all variables come out with the expected sign (recall that $\sigma^{2}$ affects the absolute value of the risk premium through the parameter $\theta$ ) and are mostly highly significant. The results obtained moreover clearly show that both $A_{t}$ and $R_{t}$ are strongly affected by the expected future exchange rate. The conditional variance of the exchange rate also appears as a major determinant of $R_{t}$ and, although less significantly so, of $A_{t}$. These results therefore illustrate and do globally corroborate our analysis of the insulation properties of the dual market cum capital controls on the official spot and forward markets.

\section{Conclusions}

Changes in the timing of international trade payments as well as arbitrage between the spot and the forward market disrupt the functioning of a dual exchange market, even when complete separation between the official and the financial segments is postulated. We have examined how capital controls imposed on the official spot and forward markets work to preserve the insulation properties of the dual market. Spot market controls operate as increases in transaction costs associated with changes in the timing of payments. Quantitative controls on forward positions are parameterized in a coefficient which also describes agents' attitude towards risk and have effects similar to those of an increase in risk aversion. Imposition of both types of controls increase deviations from uncovered interest parity, the spot controls by increasing deviations from covered interest parity, the forward controls by increasing the forward risk premium.

Although our analysis has been inspired by the experience of the Belgo-Luxembourg dual market, its applicability goes beyond this particular case. Our model can indeed be construed to represent an economy in which all transactions take place on a unified market, but where, because of the curtailment of other capital transactions, changes in the timing of trade receipts and payments and in the extent of forward cover of commercial transactions are quasi the only source of speculative capital flows. Some LDCs come close to this kind of economy, in which controls of the type analyzed here are pervasive and where the black exchange market plays the role of the free financial market in a dual system. 


\section{Appendix}

\section{Rational Expectations Solution}

To keep the analysis tractable we focus on the dynamics of the official exchange rates around their steady state, postulating steady state values for the other variables (the domestic price level, the financial exchange rates) which a full structural model would include (see Black and Salemi 1988 for a similar approach). Interventions are completely sterilized $(\omega=0)$. Exogenous uncertainty is limited to $u_{t}$ and $I_{d t}$ (see (17) and (21)). The dynamics is therefore exclusively the consequence of exporters' and importers' decisions concerning their forward operations and payment timing. It is introduced through $S_{t}$, the net spot sale of foreign currency resulting from period $t-1$ decision not to cover completely exports receipts (import payments) due at $t$. Given equilibrium in the forward market at $t-1, S_{t}=$ $\left(E_{t-1} w_{t}-f_{t-1}\right) / \theta$, where $E_{t-1} w_{t}$ is the rationally expected period $t$ spot rate, given the period $t-1$ information set. The unconditional expected steady state values of $f$ and $w$ are $\hat{f}=C / \varrho$ and $\hat{w}=w^{*}$ (see (20), (21)). The stationary forward rate is equal to the nominal exchange rate which equilibrates the commercial balance.

With $\omega=0$ it is possible to compute the following rational expectation path for $w_{t}$ (Pesaran 1987, p. 115):

with

$$
\begin{aligned}
& w_{t}=\mu_{1} w_{t-1}+\left(1-\mu_{1}\right) w^{*}-\frac{1}{1-\lambda \mu_{1}} \frac{\gamma+\theta+\varrho \gamma \theta}{\Omega}\left(u_{t}-I_{d t}\right) \\
& \mu_{1}=x-\sqrt{\left(x^{2}-b\right)}, \quad \text { where } x=(1+\varrho \gamma+\Omega) / 2, b=r / i ; \\
& \Omega=g(\gamma+\theta+\varrho \gamma \theta)+(1+\varrho \theta) r / i ; \lambda=1 / \Omega ; \\
& \text { and } E\left(u_{t+1}\right)=E\left(I_{d t+1}\right)=0 .
\end{aligned}
$$

This simple dynamic solution exhibits the familiar saddle path characteristic, $\mu_{1}$ being the stable root $\left(0<\mu_{1}<1\right)$. The coefficient of $\left(u_{t}-I_{d t}\right)$ can be expected to be positive for a large number of possible combinations of parameters. The one-period-ahead conditional variance of the exchange rate, $\sigma^{2}$, is then equal to:

$$
\sigma^{2}=\left[\frac{\gamma+\theta+\varrho \gamma \theta}{\left(1-\lambda \mu_{1}\right) \Omega}\right]^{2} \sigma_{u}^{2},
$$

where $\sigma_{u}^{2}$ is the variance of $\left(u_{t}-I_{d t}\right)$. Note that this is only an implicit solution for $\sigma^{2}$, as the risk parameter $\theta$ which appears in the RHS of (A.2) is a function of $\sigma^{2}$ (see (20)). As an illustration of the implications of (A.1) and (A.2), consider the effects of a change in the parameter $g$ 
which measures the intensity of the authorities' interventions. An increase in $g$ lowers $\mu_{1}$ and therefore increases the speed at which $w_{t}$ converges towards $w^{*}$. The increase in $g$ also lowers the coefficient of $\sigma_{u}^{2}$ in the RHS of (A.2) which reflects the stabilizing impact of interventions on the conditional variance of the exchange rate $\left(\sigma^{2}\right)$.

\section{List of Symbols}

$\begin{array}{ll}\alpha & =\text { coefficient of absolute risk aversion } \\ \beta, \delta, \gamma & =\text { exporter's, importer's and average transaction cost } \\ \eta_{x} & =\text { export price elasticity } \\ \theta & =\text { capital control parameter } \\ \pi & =\text { profit function } \\ \sigma^{2} & =\text { conditional variance of exchange rate } \\ \omega & =\text { sterilization coefficient } \\ A_{t} & =\text { deviation from covered interest parity } \\ C & =\text { exogenous net exports } \\ D_{m t} & =\text { foreign currency down-payment actually paid by im- } \\ \bar{D}_{m} & \text { porters } \\ D_{x t} & =\text { foreign customary level of importers' down-payment } \\ \bar{D}_{x} & \text { porters } \\ \text { DUIP } & =\text { customary level of exporters' received down-payment } \\ f_{t} & =\text { one-period forward rate prevailing at time } t \\ g & =\text { intensity of central bank intervention with respect to the } \\ & \text { spot rate } \\ H_{m t} & =\text { importer's purchase of forward foreign currency } \\ H_{x t} & =\text { exporter's sale of forward foreign currency } \\ i_{t}-1, r_{t}-1= & \text { foreign and domestic money rate } \\ I_{t} & =\text { official exchange market intervention (demand for for- } \\ I_{d t} & \text { eign currency) } \\ m, n & =\text { discretionary part of intervention } \\ M_{t}, X_{t} & =\text { number of importers and of exporters } \\ p^{*}, q^{*} & =\text { volume of imports and of exports } \\ R_{t} & =\text { foreign currency price of exports and of imports } \\ S_{t} & =\text { risk premium on the forward market } \\ u_{t} & =\text { illegal transactions on the official spot market (random) } \\ & \end{array}$


$w_{t}, w^{*}, \bar{w}, \tilde{w}=$ current, parity, expected future, and future spot exchange rate (random)

$Y_{m}, Y_{x} \quad=$ importer's and exporter's income transfers

\section{Sources}

PB: Paribas Bank Brussels, Research Department; interest and exchange rate data are compiled from the financial newspaper Echo de la Bourse. Access to Datastream was also provided by Paribas. NBB: National Bank of Belgium. IRES: Institut de Recherches Economiques (University of Louvain). MINFIN: Research Department of Finance Ministry.

\section{Dat a}

Domestic interest rate: one-month $\mathrm{BF}$ interbank rate (end of month), PB; Foreign interest rate: one-month euro-DM rate (end of month), PB; Spot official rate: BF/DM rate, end of month data from PB; daily rates used to compute the variable "prob" come from NBB for the period 03/19/79 to end 85 and from Datastream (crossed $\mathrm{BF} / \mathfrak{£}$ and $\mathrm{DM} / \mathfrak{f}$ rates) before $03 / 19 / 79$.

Forward official rate: end of month, one-month $\mathrm{BF} / \mathrm{DM}$ rate, $\mathrm{PB}$; LCB, LCD: monthly index of wages and employees compensations (on a cost basis) in Belgian and German manufacturing industries, respectively: monthly interpolation of quarterly data from IRES (Séries de base de l'économie belge); 1970-73=100.

I: Interventions are computed, at constant exchange rates as changes in NBB's net foreign assets less changes of central Government's foreign currency indebtedness. From NBB (Bulletin, balance sheets of central bank) and MINFIN (Government Financial Statistics in Bulletin de Documentation).

Current account balance: monthly interpolation of current account balance published by NBB on a transactions basis.

\section{References}

Bhandari, J. S., and B. Decaluwe (1987). A Stochastic Model of Incomplete Separation between Commercial and Financial Exchange Markets. Journal of International Economics, Vol. 22, pp. 25-55.

Black, S.W., and M.K. Salemi (1988). FIML Estimation of the Dollar-Deutschemark Risk Premium in a Portfolio Model. Journal of International Economics, Vol. 25, pp. 205-224. 
Claassen, E.-M., and C. Wyplosz (1982). Contrôle des Mouvements de Capitaux: Quelques Principes de l'Expérience Française. Annales de l'Insee, No.47/48, pp. 629-659.

Danthine, J.P. (1978). Information, Futures Prices and Stabilizing Speculation. Journal of Economic Theory, Vol. 17, pp. 79-98.

Ethier, W. (1973). International Trade and the Forward Exchange Market. American Economic Review, Vol. 63, pp. 494-503.

Frankel, J.A., and K.A. Froot (1986). Interpreting Tests of Forward Discount Bias Using Survey Data on Exchange Rate Expectations. NBER Working Paper Series No. 1963. Cambridge, Mass.

Frenkel, J. A., and A. Razin (1989). Exchange Rate Management Viewed as Tax Policies. European Economic Review, Vol. 33/34, pp. 761-781.

Froot, K. A., and J. A. Frankel (1989). Forward Discount Bias: Is It an Exchange Risk Premium? Quarterly Journal of Economics, Vol. 104, pp. 139-161.

Gardner, G.W. (1985). Money, Prices and the Current Account in a Dual Exchange Rate Regime. Journal of International Economics, Vol. 18, pp. 321-338.

Giavazzi, F., and A. Giovannini (1989). Limiting Exchange Rate Flexibility: the European Monetary System. Cambridge: The MIT Press.

Giovannini, A. (1988). Capital Controls and Public Finance: The Experience of Italy. In: F. Giavazzi and L. Spaventa (eds.), High Public Debt: The Italian Experience, pp. 177-211. Cambridge: Cambridge University Press.

Gros, D. (1988). Dual Exchange Rates in the Presence of Incomplete Market Separation: Long-Run Effectiveness and Policy Implications. IMF Staff Papers, pp. 437460.

Guidotti, P.E., and C. A. Végh (1992). Macroeconomic Interdependence under Capital Controls: A Two-Country Model of Dual Exchange Rates. Journal of International Economics, Vol. 32, pp. 353-367.

Holthausen, D. M. (1979). Hedging and the Competitive Firm under Price Uncertainty. American Economic Review, Vol. 69, pp. 989-995.

International Monetary Fund (1982). Annual Report on Exchange Rate Restrictions. Washington, D.C.

- (1989). Annual Report. Washington, D.C.

Janson, G. (1981). L'Institut Belgo-Luxembourgois du Change et le Contrôle des Changes. In: Association Belge des Banques (ed.), La Protection de L'Entreprise contre le Risque de Change. Aspects et Documents No. 2, Brussels, pp. 29-43.

Kawai, M., and I. Zilcha (1986). International Trade with Forward-Futures Markets under Exchange Rate and Price Uncertainty. Journal of International Economics, Vol. 20, pp. 83-98.

Krasker, W. (1980). The Peso Problem in Testing the Efficiency in Forward Markets. Journal of Monetary Economics, Vol. 6, pp. 269-276.

Newbery, D. M.G. (1988). On the Accuracy of the Mean-Variance Approximation for Futures Markets. Economics Letters, Vol. 28, pp. 63-68.

Newbery, D. M. G., and J. E. Stiglitz (1981). The Theory of Commodity Price Stabilization. Oxford: Oxford University Press. 
Obstfeld, M. (1988). Competitiveness, Realignments and Speculation: The Role of Financial Markets. In: F. Giavazzi, S. Micossi, and M. Miller (eds.), The European Monetary System, pp. 232-251. Cambridge: Cambridge University Press.

Pesaran, M.H. (1987). The Limits to Rational Expectations. Oxford: Basil Blackwell.

Rose, A.K.R., and L.E.O. Svensson (1991). Expected and Predicted Realignments: The FF/DM Exchange Rate During the EMS. Board of Governors of the Federal Reserve System, International Finance Discussion Papers No. 395. Washington, D.C.

Stein, J. L. (1985). Exchange Rate Management with Rational Expectations but Diverse Precisions. In: J. S. Bhandari (ed.), Exchange Rate Management Under Uncertainty, pp. 96-125. Cambridge: The MIT Press.

Svensson, L.E. O. (1990). The Foreign Exchange Risk Premium in a Target Zone with Devaluation Risk. NBER Working Paper Series No. 3466. Cambridge, Mass.

Abstract: Capital Controls and International Trade Finance in a Dual Exchange Rate Regime: The Belgian Experience Post-Mortem. - The purpose of the paper is to model "leads and lags" capital flows on the official segment of a dual exchange market and to examine the effects of various types of capital controls imposed by authorities on the official spot and forward exchange markets. The focus of the analysis is the degree of insulation provided by a "dual exchange market cum capital controls" in face of a speculative crisis. The crucial variables in this respect are the deviation from covered interest parity and the forward risk premium. Results of the theoretical model are confronted with empirical evidence over the 1975-85 period.

JEL No. F31, F32, F36

Zus a m menfassung: Kapitalkontrollen und die Finanzierung des internationalen Handels in einem dualen Wechselkurssystem. Rückblick auf die belgischen Erfahrungen. - Der Zweck dieses Aufsatzes ist es, Leads and Lags bei Kapitalströmen im offiziellen Teil eines segmentierten Devisenmarktes zu modellieren und zu untersuchen, welche Wirkungen verschiedene behördlich auferlegte Kapitalkontrollen auf die Kassaund Terminkurse der offiziellen Devisenmärkte haben. Die Analyse konzentriert sich darauf zu ermitteln, welches Ausmaß an Abschottung ein ,ddualer Devisenmarkt mit Kapitalkontrollen" im Falle einer spekulativen Krise ermöglicht. Die entscheidenden Variablen in dieser Hinsicht sind die Abweichung von der gesicherten Zinsparität und die Risikoprämie auf dem Terminmarkt. Die Ergebnisse aus dem theoretischen Modell werden dem empirischen Befund aus der Periode 1975-85 gegenübergestellt. 